\title{
Active Disturbance Rejection Control of Three-Phase LCL Grid-Connected Inverter under Unbalanced Grid Voltage
}

\author{
Jianfeng Yang and Ningning Meng $(D)$ \\ School of Automation and Electrical Engineering, Lanzhou Jiaotong University, Lanzhou730070, China \\ Correspondence should be addressed to Ningning Meng; 11200374@stu.lzjtu.edu.cn
}

Received 2 December 2021; Revised 28 December 2021; Accepted 27 January 2022; Published 14 February 2022

Academic Editor: Zhixiang Zou

Copyright (C) 2022 Jianfeng Yang and Ningning Meng. This is an open access article distributed under the Creative Commons Attribution License, which permits unrestricted use, distribution, and reproduction in any medium, provided the original work is properly cited.

\begin{abstract}
When the three-phase LCL grid-connected inverter operates under the condition of unbalanced grid voltage, the influence of the negative sequence component in the grid voltage will cause the grid-connected inverter system to produce active and reactive dual-frequency interference. This will cause the grid-side current to have many low-order harmonics, mainly the third harmonic, which does not conform the IEEE-Std. 929-2000 standard. In order to solve this problem, this paper designs a current autodisturbance-rejection controller, which speeds up the tracking response speed of the system and reduces the harmonic content of the grid-side current under unbalanced conditions. At the same time, optimize the phase-locked loop structure and introduce a notch filter in the modulation link to eliminate the third low-frequency harmonic components and further improve the quality of the grid-side current waveform. Finally, the correctness of the control strategy suggested in this paper is verified by MATLAB/ Simulink simulation
\end{abstract}

\section{Introduction}

As China's "carbon peak and carbon neutrality" goal is put forward, many renewable energy sources will be connected to the grid [1-3], and as the main power electronic equipment between renewable energy and the grid, threephase inverters have been widely used [4-6]. The threephase LCL type grid-connected inverter $[7,8]$ has the advantages of better harmonic suppression and smaller size in its filtering link, and it has become more and more popular in renewable new energy systems such as photovoltaic power generation and wind power generation [9-11].

The research of three-phase LCL type grid-connected inverter is mainly concentrated on the condition of threephase grid voltage balance [12-14]. However, in actual systems, unbalanced grid voltages are common, which will cause harmonic components to appear in the grid-connected current of the three-phase LCL grid-connected inverter and caused the performance of the grid-connected inverter to deteriorate [14-16]. In response to this problem, researchers have successively suggested some solutions. Through independent control of the positive and negative sequence components of the current, the purpose of eliminating active power fluctuations is achieved, but the positive and negative sequence current components need to be extracted, and the control structure is complicated $[17,18]$. Added the specific harmonic order of the grid-connected current suppression item to the cost function proposed by model predictive control, which reduced the use of sensors, but the control algorithm was more complicated $[19,20]$. On the other hand, the traditional PI controller can be used for control based on the extraction of positive and negative sequence components. This solution is easy to implement, but the amount of calculation is too large $[21,22]$. The use of the PR controller does not need to separate the positive and negative sequence quantities, which improves the control speed of the system, but the parameter tuning needs to consider different circuit parameters $[20,23,24]$. Guzman's team proposed to achieve flexible control of the total harmonic distortion (THD) of the grid-connected current by changing the current command coefficient [25]. In order to effectively suppress the pulsation of the output power of the system, a 
resonant controller was designed [26]. In addition, the extraction method of positive and negative sequence components commonly used in control strategies under unbalanced grid voltage has also attracted the attention of many scholars. Based on the extraction method of ANF-PLL, its structure has been simplified compared with the traditional method, but the scope of application is small [27-29]. In addition, DSOGI-PLL is used to propose the positive and negative sequence components of the grid voltage, and the filter is used to improve its performance, but the calculation process is complicated [27]. The digital notch filter can also be used to extract the positive and negative sequence components of the grid voltage. Although its structure is simple, its performance will be affected in a complex grid environment [30].

This paper proposes a new type of control algorithm on the basis of existing research. First, establish the mathematical model of the three-phase LCL grid-connected inverter in the two-phase synchronous rotating coordinate system and analyze that when the grid voltage is unbalanced, the positive and negative sequence components in the grid voltage will result in many harmonics in the grid-connected current of the inverter. It is suggested to reduce the influence of harmonics on the phase-locked loop structure through a front low-pass filter and combine the optimized phaselocked structure to design a current auto-disturbance-rejection controller, which realizes the safety and stability run of the grid-connected inverter under unbalanced grid voltage. Finally, a simulation model is established through MATLAB/Simulink, and the feasibility and effectiveness of the control strategy are verified under balanced and unbalanced grid voltages.

\section{Working Analysis of Three-Phase LCL Grid Connected Inverter System}

The topology of the three-phase LCL grid-connected inverter is shown in Figure 1, In this system, $u_{\mathrm{dc}}$ denotes DC side voltage, $C$ is the DC side filter capacitor, $S 1-S 6$ are IGBT switch tubes, $u_{\text {invk }}$ denotes AC side output voltage, $i_{k}$ is the AC side output current, $\mathrm{L}_{k}$ and $\mathrm{C}_{k}$ are AC side filter inductance and filter capacitor, respectively, $i_{c k}$ is the AC side filter capacitor branch current, $u_{c k}$ is the filter capacitor voltage, $\mathrm{L}_{\mathrm{g} k}$ is the grid-side filter inductance, and $u_{\mathrm{g} k}$ and $i_{\mathrm{g} k}$ are the grid voltage and the grid-connected current, respectively, where $k=a, \mathrm{~b}, \mathrm{c}$.

According to Kirchhoff's law of voltage and current, the AC side output current, grid-side output current, and AC side filter capacitor voltage equations of the three-phase LCL grid-connected inverter in the three-phase static coordinate system are obtained.

$$
\left\{\begin{array}{l}
\frac{\mathrm{d}}{\mathrm{d} t}\left[\begin{array}{c}
i_{\mathrm{ga}} \\
i_{\mathrm{gb}} \\
i_{\mathrm{gb}}
\end{array}\right]=\frac{1}{\mathrm{~L}_{\mathrm{g}}}\left[\begin{array}{l}
u_{\mathrm{ca}}-u_{\mathrm{ga}} \\
u_{\mathrm{cb}}-u_{\mathrm{gb}} \\
u_{\mathrm{cc}}-u_{\mathrm{gc}}
\end{array}\right], \\
\frac{\mathrm{d}}{\mathrm{d} t}\left[\begin{array}{l}
i_{\mathrm{a}} \\
i_{\mathrm{b}} \\
i_{\mathrm{c}}
\end{array}\right]=\frac{1}{\mathrm{~L}}\left[\begin{array}{l}
u_{\mathrm{inva}}-u_{\mathrm{ca}} \\
u_{\mathrm{invb}}-u_{\mathrm{cb}} \\
u_{\mathrm{invc}}-u_{\mathrm{cc}}
\end{array}\right], \\
\frac{\mathrm{d}}{\mathrm{d} t}\left[\begin{array}{l}
u_{\mathrm{ca}} \\
u_{\mathrm{cb}} \\
u_{\mathrm{cc}}
\end{array}\right]=\frac{1}{\mathrm{C}}\left[\begin{array}{l}
i_{\mathrm{a}}-i_{\mathrm{ga}} \\
i_{\mathrm{b}}-i_{\mathrm{gb}} \\
i_{\mathrm{c}}-i_{\mathrm{gc}}
\end{array}\right] .
\end{array}\right.
$$

Get in the two-phase synchronous rotating coordinate system by Park transformation:

$$
\left\{\begin{array}{l}
\frac{\mathrm{d}}{\mathrm{d} t}\left[\begin{array}{l}
i_{\mathrm{gd}} \\
i_{\mathrm{gq}}
\end{array}\right]=\frac{1}{\mathrm{~L}_{\mathrm{g}}}\left[\begin{array}{l}
u_{\mathrm{cd}}-u_{\mathrm{gd}} \\
u_{\mathrm{cq}}-u_{\mathrm{gq}}
\end{array}\right]+\left[\begin{array}{cc}
0 & \omega_{\mathrm{g}} \\
-\omega_{\mathrm{g}} & 0
\end{array}\right]\left[\begin{array}{l}
i_{\mathrm{gd}} \\
i_{\mathrm{gq}}
\end{array}\right], \\
\frac{\mathrm{d}}{\mathrm{d} t}\left[\begin{array}{l}
i_{\mathrm{d}} \\
i_{\mathrm{q}}
\end{array}\right]=\frac{1}{\mathrm{~L}}\left[\begin{array}{l}
u_{\mathrm{invd}}-u_{\mathrm{cd}} \\
u_{\mathrm{invq}}-u_{\mathrm{cq}}
\end{array}\right]+\left[\begin{array}{cc}
0 & \omega_{\mathrm{g}} \\
-\omega_{\mathrm{g}} & 0
\end{array}\right]\left[\begin{array}{l}
i_{\mathrm{d}} \\
i_{\mathrm{q}}
\end{array}\right], \\
\frac{\mathrm{d}}{\mathrm{d} t}\left[\begin{array}{l}
u_{\mathrm{cd}} \\
u_{\mathrm{cq}}
\end{array}\right]=\frac{1}{\mathrm{C}}\left[\begin{array}{l}
i_{\mathrm{d}}-i_{\mathrm{gd}} \\
i_{\mathrm{q}}-i_{\mathrm{gq}}
\end{array}\right]+\left[\begin{array}{cc}
0 & \omega_{\mathrm{g}} \\
-\omega_{\mathrm{g}} & 0
\end{array}\right]\left[\begin{array}{l}
u_{\mathrm{cd}} \\
u_{\mathrm{cq}}
\end{array}\right] .
\end{array}\right.
$$

When the grid voltage is balanced, a reasonable design of the system controller can easily realize the control of the grid-connected inverter. However, when the grid voltage is unbalanced, because the grid voltage will produce positive and negative sequence components, the interaction between the two will cause the output power to fluctuate, which will lead to numerous low-frequency harmonic components in the grid-connected current and seriously affect the performance of the grid-connected inverter.

When the three-phase grid voltage is unbalanced, according to the symmetrical component method, the grid voltage expression is 


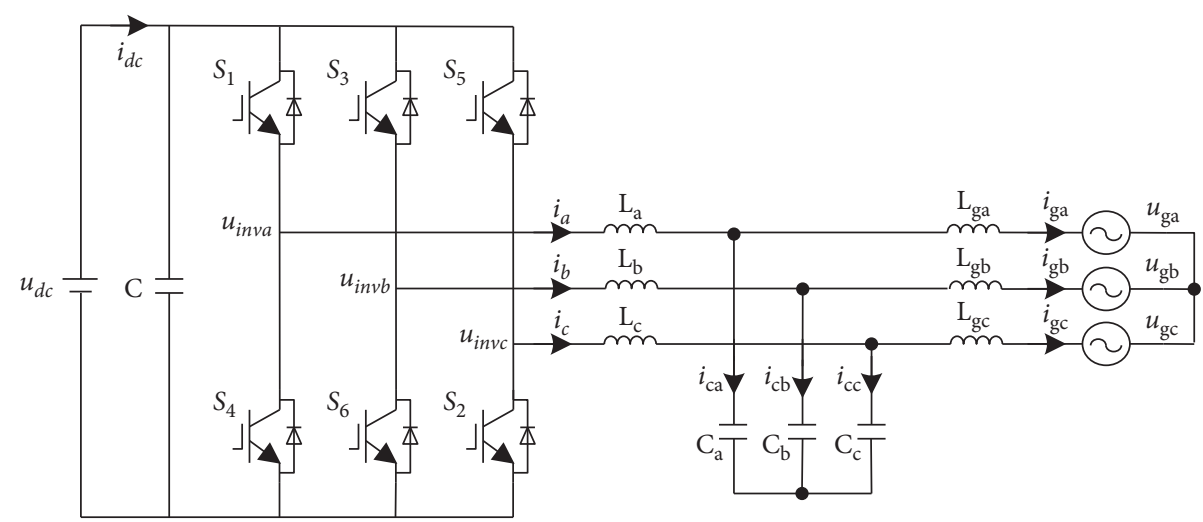

Figure 1: Topology of the three-phase LCL grid-connected inverter.

$$
\begin{aligned}
{\left[\begin{array}{l}
u_{\mathrm{ga}} \\
u_{\mathrm{gb}} \\
u_{\mathrm{gc}}
\end{array}\right]=} & V_{s}^{+}\left[\begin{array}{c}
\cos \left(\omega t+\varphi^{+}\right) \\
\cos \left(\omega t+\varphi^{+}-120^{\circ}\right) \\
\cos \left(\omega t+\varphi^{+}+120^{\circ}\right)
\end{array}\right] \\
& +V_{s}^{-}\left[\begin{array}{c}
\cos \left(-\omega t+\varphi^{-}\right) \\
\cos \left(-\omega t+\varphi^{-}-120^{\circ}\right) \\
\cos \left(-\omega t+\varphi^{-}+120^{\circ}\right)
\end{array}\right],
\end{aligned}
$$

where $V_{s}^{+1}$ and $V_{s}^{-1}$ are the amplitudes of the positive and negative fundamental components, respectively. $\varphi^{+}$and $\varphi^{-}$ are the phases of the positive and negative fundamental components, respectively. $\theta$ represents the phase angle of the grid voltage.

$$
\begin{aligned}
{\left[\begin{array}{l}
u_{\mathrm{gd}+1} \\
u_{\mathrm{gq}+1}
\end{array}\right]=} & V_{\mathrm{s}}^{+1}\left[\begin{array}{l}
\cos \left(\omega t+\varphi^{+1}-\theta\right) \\
\sin \left(\omega t+\varphi^{+1}-\theta\right)
\end{array}\right] \\
& +V_{\mathrm{s}}^{-1}\left[\begin{array}{c}
\cos \left(-\omega t+\varphi^{-1}-\theta\right) \\
\sin \left(-\omega t+\varphi^{-1}-\theta\right)
\end{array}\right], \\
{\left[\begin{array}{l}
u_{\mathrm{gd}-1} \\
u_{\mathrm{gq}-1}
\end{array}\right]=} & V_{\mathrm{s}}^{+1}\left[\begin{array}{c}
\cos \left(\omega t+\varphi^{+1}+\theta\right) \\
\sin \left(\omega t+\varphi^{+1}+\theta\right)
\end{array}\right] \\
& +V_{\mathrm{s}}^{-1}\left[\begin{array}{c}
\cos \left(-\omega t+\varphi^{-1}+\theta\right) \\
\sin \left(-\omega t+\varphi^{-1}+\theta\right)
\end{array}\right] .
\end{aligned}
$$

Using the voltage and current components under the two-phase synchronous rotating coordinate, the instantaneous power expression on the grid side can be obtained as

$$
\begin{gathered}
\left\{\begin{array}{l}
p(t)=p_{\mathrm{o}}+p_{\mathrm{c} 2} \cos (2 \omega t)+p_{\mathrm{s} 2} \sin (2 \omega t) \\
q(t)=q_{\mathrm{o}}+q_{\mathrm{c} 2} \cos (2 \omega t)+q_{\mathrm{s} 2} \sin (2 \omega t)
\end{array},\right. \\
{\left[\begin{array}{c}
p_{\mathrm{o}} \\
p_{\mathrm{c} 2} \\
p_{\mathrm{s} 2} \\
q_{\mathrm{o}} \\
q_{\mathrm{c} 2} \\
q_{\mathrm{s} 2}
\end{array}\right]=1.5\left[\begin{array}{cccc}
u_{\mathrm{gd}}^{+} & u_{\mathrm{gq}}^{+} & u_{\mathrm{gd}}^{-} & u_{\mathrm{gq}}^{-} \\
u_{\mathrm{gd}}^{-} & u_{\mathrm{gq}}^{-} & u_{\mathrm{gd}}^{+} & u_{\mathrm{gq}}^{+} \\
u_{\mathrm{gq}}^{-} & -u_{\mathrm{gd}}^{-} & -u_{\mathrm{gq}}^{+} & u_{\mathrm{gd}}^{+} \\
u_{\mathrm{gq}}^{+} & -u_{\mathrm{gd}}^{+} & u_{\mathrm{gq}}^{-} & -u_{\mathrm{gd}}^{-} \\
u_{\mathrm{gq}}^{-} & -u_{\mathrm{gd}}^{-} & u_{\mathrm{gq}}^{+} & -u_{\mathrm{gd}}^{+} \\
-u_{\mathrm{gd}}^{-} & -u_{\mathrm{gq}}^{-} & u_{\mathrm{gd}}^{+} & u_{\mathrm{gq}}^{+}
\end{array}\right]\left[\begin{array}{c}
i_{\mathrm{gd}}^{+} \\
i_{\mathrm{gq}}^{+} \\
i_{\mathrm{gd}}^{-} \\
i_{\mathrm{gq}}^{-}
\end{array}\right],}
\end{gathered}
$$

where $u^{+\mathrm{gd}}, u^{+\mathrm{gq}}, u^{\text {-gd }}$, and $u^{\text {-gq }}$ are the positive and negative sequence components of the voltage, respectively. $I+\mathrm{gd}$, $i^{+\mathrm{gq}}, i^{\text {-gd }}$, and $i^{\text {-gq }}$ are the positive and negative sequence components of the current, respectively.

It can be seen from (5) that the instantaneous active power and reactive power in the three-phase unbalanced power grid will produce double pulsation, and the gridconnected inverter will output unbalanced grid-connected current with many harmonics [15].

\section{Control Strategy under Unbalanced Grid Voltage}

Aiming at the problems of the three-phase LCL grid-connected inverter mentioned above under the three-phase unbalanced power grid conditions, this paper proposes an active disturbance rejection control strategy based on an improved lock loop, as shown in Figure 2. Through a phaselocked loop to obtain the grid voltage phase; the gridconnected current is sampled, and the current component in the $d-q$ coordinate system is obtained through coordinate transformation; the difference between the given current and the sampled current is passed through the current controller and then added to the voltage component. After coordinate transformation, the drive signal is finally obtained through SVPWM modulation to realize system control.

In formula (4), when the positive sequence rotation axis components $\mathrm{gd}^{+1}$ and $\mathrm{gq}^{+1}$ and the positive sequence component $V_{s}^{+1}$ will coincide, the phase-locked loop can accurately extract the phase of the three-phase power grid. Formula (4) is transformed into formula (6)

$$
\begin{aligned}
{\left[\begin{array}{l}
u_{\mathrm{gd}+1} \\
u_{\mathrm{gq}+1}
\end{array}\right]=} & {\left[\begin{array}{l}
u_{\mathrm{gd}}^{+1} \\
u_{\mathrm{gq}}^{+1}
\end{array}\right]+V_{\mathrm{s}}^{-1} \cos \varphi\left[\begin{array}{c}
\cos \left(-2 \theta^{\prime}\right) \\
-\sin \left(2 \theta^{\prime}\right)
\end{array}\right] } \\
& +V_{\mathrm{s}}^{-1} \sin \varphi\left[\begin{array}{c}
\sin \left(2 \theta^{\prime}\right) \\
\cos \left(-2 \theta^{\prime}\right)
\end{array}\right], \\
{\left[\begin{array}{l}
u_{\mathrm{gd}-1} \\
u_{\mathrm{gq}-1}
\end{array}\right]=} & {\left[\begin{array}{l}
u_{\mathrm{gd}}^{-1} \\
u_{\mathrm{gq}}^{-1}
\end{array}\right]+V_{\mathrm{s}}^{+1}\left[\begin{array}{c}
\cos \left(2 \theta^{\prime}\right) \\
\sin \left(2 \theta^{\prime}\right)
\end{array}\right] . }
\end{aligned}
$$

It can be seen from formula (6) that when the grid voltage is unbalanced, the $d$-axis and $q$-axis components of the grid 


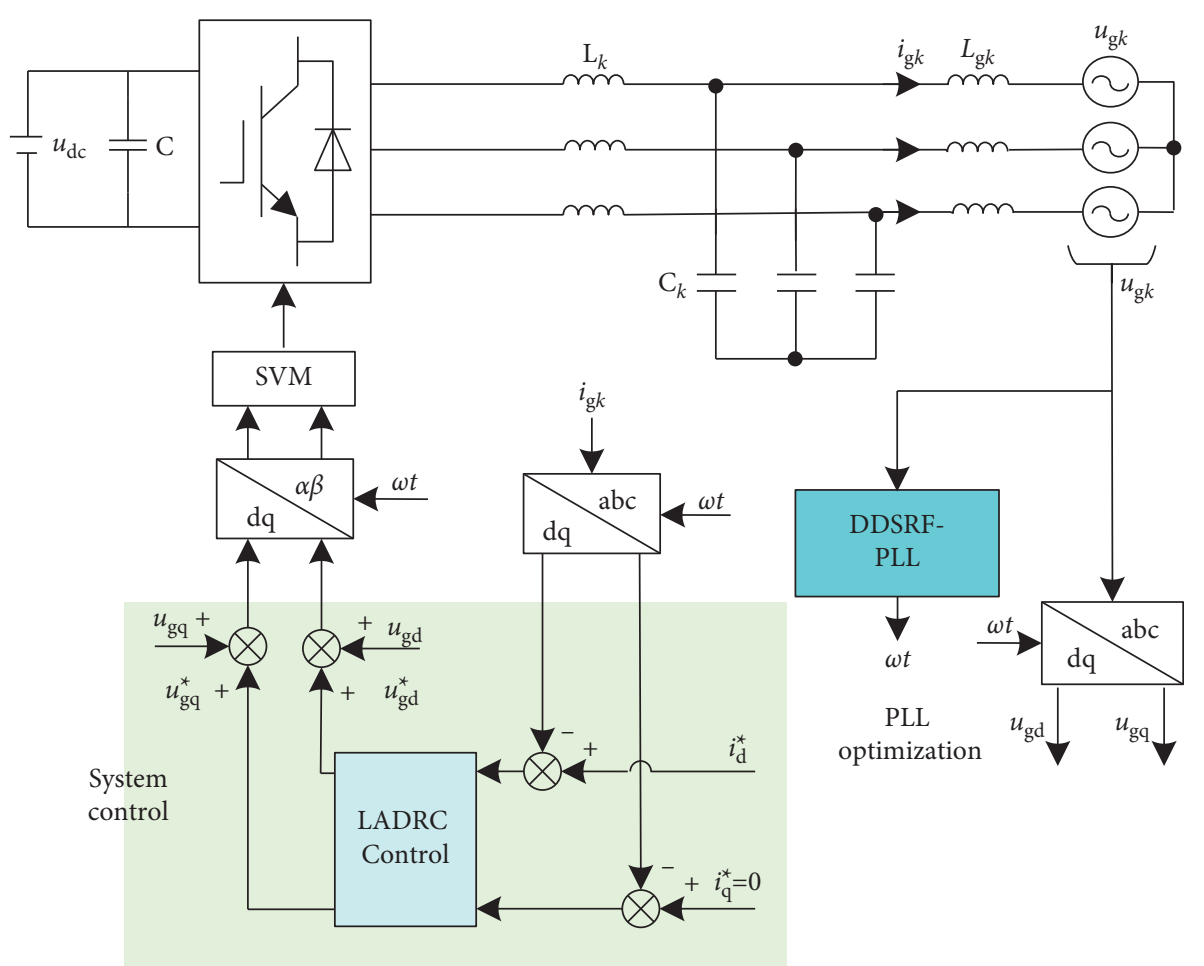

Figure 2: Control block diagram of grid-connected inverter under unbalanced grid conditions.

voltage will superimpose twice the frequency disturbance, and there is a coupling relationship with the three-phase grid voltage. Therefore, it is necessary to adopt a corresponding phase-locked loop with a decoupling network to solve the problems such as voltage oscillation caused by this. The ordinary phase-locked loop structure is not applicable under this working condition, which is easily affected by the working condition, resulting in a certain degree of oscillation in the output frequency and phase, and affects the response time and control effect of the entire control system. In response to this problem, the phase-locked structure in Figure 2 uses a phaselocked loop (DDSRF-PLL) based on a decoupled multisynchronous coordinate system, which uses positive and negative sequence double $\mathrm{d}-\mathrm{q}$ rotation coordinate transformation as the phase detector of the phase-locked loop structure. Through mathematical operation, the interference component in the unbalanced grid voltage is eliminated, and the influence of the unbalanced grid voltage on the performance of the phase-locked loop is effectively overcome. Its decoupling network transformation expression is

$$
\begin{aligned}
{\left[\begin{array}{l}
u_{\mathrm{gd}+1}^{*} \\
u_{\mathrm{gq}+1}^{*}
\end{array}\right]=} & {\left[\begin{array}{l}
u_{\mathrm{gd}+1} \\
u_{\mathrm{gq}+1}
\end{array}\right]-\bar{u}_{\mathrm{gd}-1}\left[\begin{array}{l}
\cos \left(-2 \theta^{\prime}\right) \\
-\sin \left(2 \theta^{\prime}\right)
\end{array}\right] } \\
& -\bar{u}_{\mathrm{gq}-1}\left[\begin{array}{l}
\sin \left(2 \theta^{\prime}\right) \\
\cos \left(2 \theta^{\prime}\right)
\end{array}\right], \\
{\left[\begin{array}{l}
u_{\mathrm{gd}-1}^{*} \\
u_{\mathrm{gq}-1}^{*}
\end{array}\right]=} & {\left[\begin{array}{l}
u_{\mathrm{gd}-1} \\
u_{\mathrm{gq}-1}
\end{array}\right]-\bar{u}_{\mathrm{gd}+1}\left[\begin{array}{l}
\cos \left(-2 \theta^{\prime}\right) \\
-\sin \left(2 \theta^{\prime}\right)
\end{array}\right] } \\
& -\bar{u}_{\mathrm{gq}+1}\left[\begin{array}{l}
\sin \left(2 \theta^{\prime}\right) \\
\cos \left(2 \theta^{\prime}\right)
\end{array}\right] .
\end{aligned}
$$

It can be seen that the $d-q$ axis component after decoupling network transformation suppresses the unbalanced influence caused by the second harmonic generated by the negative sequence component.

In the control strategy of Figure 2, although the PI controller of DDSRF-PLL can play a filtering role to a certain extent, the dynamic response speed will be slower. In the actual three-phase unbalanced situation, the harmonic components generated by the grid voltage are more complicated, and the influence of multiple harmonics on the three-phase LCL grid-connected inverter cannot be realized by the PI controller alone. In response to this problem, this paper proposes to introduce a low-pass filter to filter before PI control, to reduce the influence of multiple harmonics on the phase-locking performance of DDSRF-PLL, and to improve the accuracy of the phase-locked structure. The improved DDSRF-PLL phase-locked structure is shown in Figure 3.

It can be seen from Figure 4 that when the three-phase grid voltage is unbalanced under steady-state conditions, DDSRF-PLL can not only accurately detect the phase of the positive sequence voltage but also detect the amplitude and frequency. When the voltage phase changes suddenly, the phase can be relocked within $10 \mathrm{~ms}$, which proves that its dynamic performance is relatively good.

\section{Loop Controller Design}

As the loop controller of the three-phase LCL inverter, the linear active disturbance rejection controller mainly includes linear tracking differential controller (LTD), linear extended 


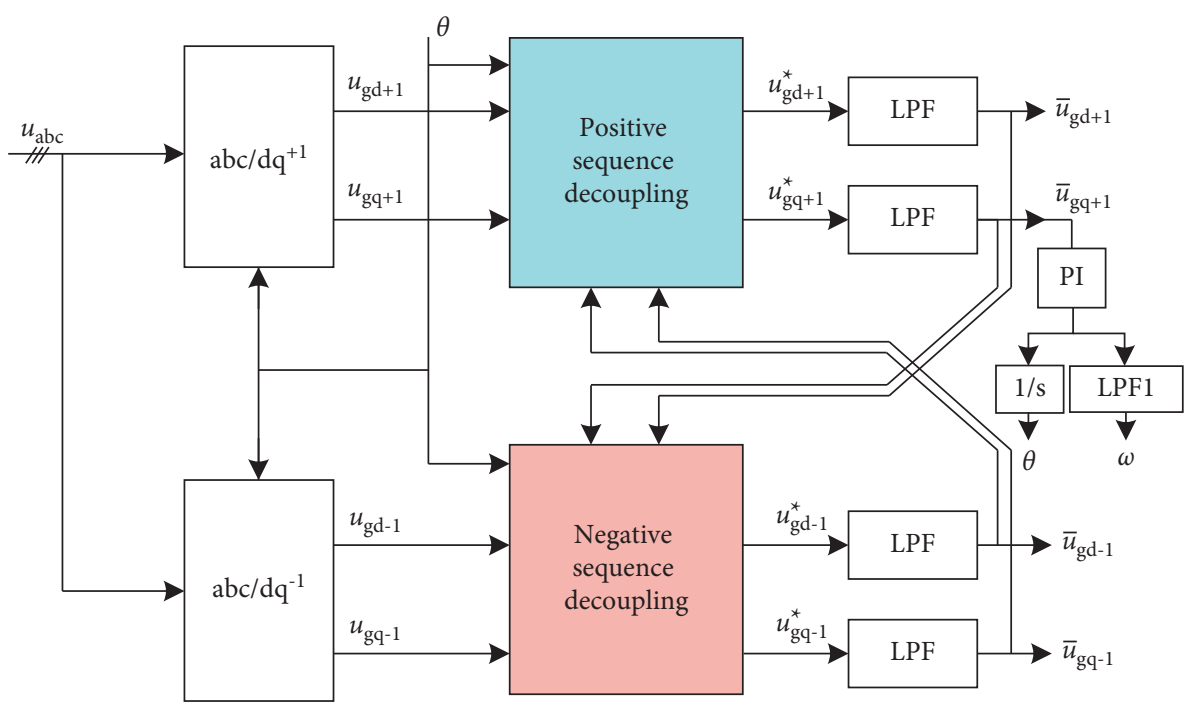

FIGURE 3: Block diagram of the optimized DDSRF-PLL control.

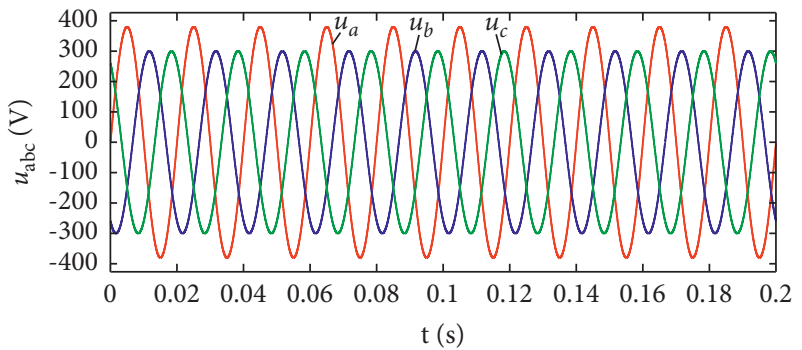

(a)

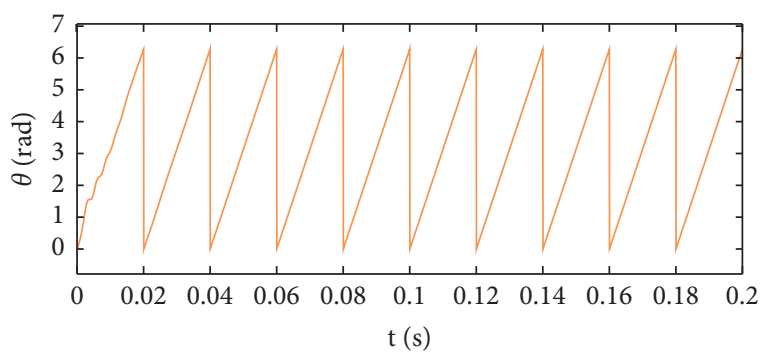

(c)

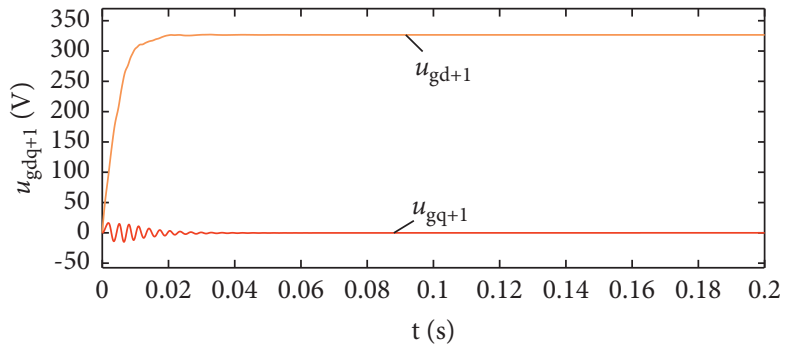

(b)

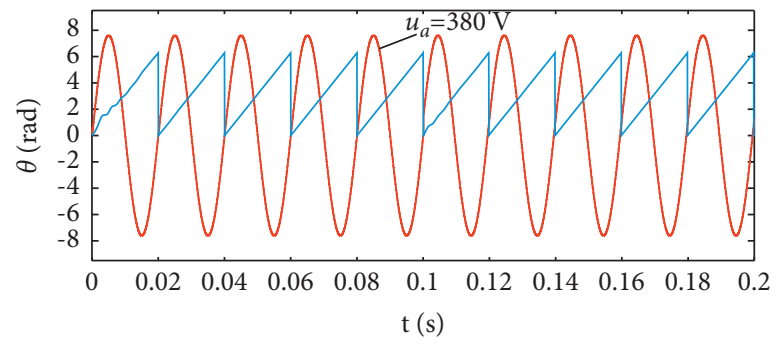

(d)

FIGURE 4: DDSRF-PLL dynamic response waveform: (a) voltage waveform when three-phase grid voltage amplitude is unbalanced, (b) DDSRF-PLL outputs $\mathrm{u}_{\mathrm{gd}+1}$ and $\mathrm{gq}_{\mathrm{g}}$, (c) DDSRF-PLL outputs angle when the voltage amplitude is unbalanced, and (d) response waveform of DDSRF-PLL at $0.1 \mathrm{~s}$ phase change.

state observer (LESO), and linear state error feedback controller (LSEF) which are shown in Figure 5.

The traditional PI controls directly uses the difference between the grid-side current reference value of the inverter and the grid-side current as the feedback control signal. The use of traditional PI controllers causes the contradiction between the inverter's grid-side current response speed and overshoot. At the same time, the three-phase LCL gridconnected inverter, as a voltage-type inverter, is prone to inrush current during the startup. Therefore, the linear active disturbance rejection controller is introduced into LTD, and the grid-side current reference value is given to the inverter. The grid-side current impact is reduced by

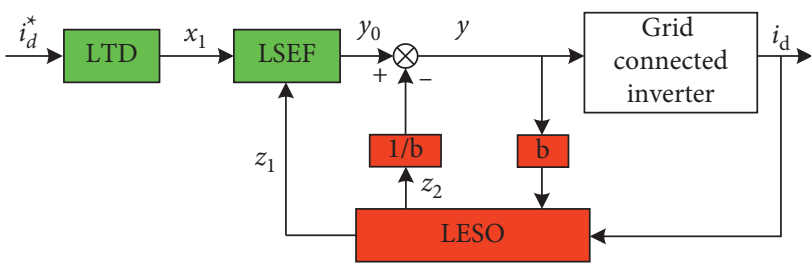

FIgURE 5: LADRC control of the current loop.

arranging the transition process, so that the system responds quickly at startup without overshoot. The specific design of LTD is 


$$
\left\{\begin{array}{l}
\dot{x}_{1}=x_{2}, \\
\dot{x}_{2}=r x_{1}-r^{2}\left(x_{1}-i_{\mathrm{d}}\right),
\end{array}\right.
$$

where $r$ is the speed factor, which is positively correlated with the controller tracking speed, and $x_{1}$ is the transition process of the inverter grid-connected current $i_{\mathrm{d}}$.

The design of the linear state observer is shown in formula (9), and it can observe the grid-side current of the three-phase LCL grid-connected inverter in real time and introduce an expanded state device to observe the internal and external disturbances of the inverter.

$$
\left\{\begin{array}{l}
\dot{z}_{1}=z_{2}-\beta_{1}\left(z_{1}-i_{\mathrm{d}}\right)+\text { by } \\
\dot{z}_{2}=-\beta_{2}\left(z_{1}-i_{\mathrm{d}}\right)
\end{array}\right.
$$

where $z_{1}$ is the real-time observation value of the gridconnected current $i_{\mathrm{d}} ; z_{2}$ is the real-time estimated value of the internal and external disturbances of the three-phase LCL inverter; and $\beta_{1}$ and $\beta_{2}$ are adjustable parameters.

The design of LSEF is specifically shown in (10), using the squared difference of the current as the feedback control quantity. Through amplifying, the error can speed up the tracking of the inverter grid-connected current $i_{\mathrm{d}}$ to the given value and speed up the system response speed. LSEF can also compensate the system in real-time based on LESO's real-time estimation of internal and external disturbances to improve the system's anti-interference ability.

$$
\left\{\begin{array}{l}
y_{0}=k\left(x_{1}^{2}-z_{1}^{2}\right), \\
y=P_{0}-\left(\frac{z_{2}}{b}\right),
\end{array}\right.
$$

where $b$ is the compensation coefficient; when $b$ increases, the system dynamic performance decreases; when $b$ decreases, the system dynamic performance increases; $k$ is the error feedback coefficient.

\section{System Modulation Strategy}

The SVM method is the most commonly used method to control the three-phase LCL grid-connected inverter. The switching state and sector division of the traditional 6-sector modulation is shown in Table 1.

Analyzing Table 1, we can get the voltage vector and sector spatial distribution as shown in Figure 6. In the figure, the effective voltage vector $U_{1} \sim U_{6}$ with an amplitude of $2 / 3 u_{\mathrm{dc}}$ divides the complex plane into 6 sectors I-VI. When $U_{s}$ runs to any sector, it can be combined by the adjacent effective voltage vector and zero vector on both sides of the sector. When $U_{s}$ rotates at a constant speed, the desired three-phase symmetrical sine wave can be obtained. $U_{0}$ and $U_{7}$ are both zero-voltage vectors with an amplitude of 0 .

It can be seen from the above that the grid-side current mainly contains the third low-frequency harmonics, and the modulated signal obtained by coordinate transformation will also contain the third-harmonic components. A notch filter can be used to eliminate the harmonics to further
TABLE 1: Relationship between switch state and voltage vector.

\begin{tabular}{ccccccc}
\hline$S_{\mathrm{a}}$ & $S_{\mathrm{b}}$ & $S_{\mathrm{c}}$ & $u_{\mathrm{a}}$ & $u_{\mathrm{b}}$ & $u_{\mathrm{c}}$ & $U_{0 \sim 7}$ \\
\hline 0 & 0 & 0 & 0 & 0 & 0 & $\boldsymbol{U}_{0}$ \\
1 & 0 & 0 & $2 / 3 u_{\mathrm{dc}}$ & $-1 / 3 u_{\mathrm{dc}}$ & $-1 / 3 u_{\mathrm{dc}}$ & $\boldsymbol{U}_{1}$ \\
1 & 1 & 0 & $1 / 3 u_{\mathrm{dc}}$ & $1 / 3 u_{\mathrm{dc}}$ & $-2 / 3 u_{\mathrm{dc}}$ & $\boldsymbol{U}_{2}$ \\
0 & 1 & 0 & $-1 / 3 u_{\mathrm{dc}}$ & $2 / 3 u_{\mathrm{dc}}$ & $-1 / 3 u_{\mathrm{dc}}$ & $\boldsymbol{U}_{3}$ \\
0 & 1 & 1 & $-2 / 3 u_{\mathrm{dc}}$ & $1 / 3 u_{\mathrm{dc}}$ & $1 / 3 u_{\mathrm{dc}}$ & $\boldsymbol{U}_{4}$ \\
0 & 0 & 1 & $-1 / 3 u_{\mathrm{dc}}$ & $-1 / 3 u_{\mathrm{dc}}$ & $1 / 3 u_{\mathrm{dc}}$ & $\boldsymbol{U}_{5}$ \\
1 & 0 & 1 & $1 / 3 u_{\mathrm{dc}}$ & $-2 / 3 u_{\mathrm{dc}}$ & $1 / 3 u_{\mathrm{dc}}$ & $\boldsymbol{U}_{6}$ \\
1 & 1 & 1 & 0 & 0 & 0 & $\boldsymbol{U}_{7}$ \\
\hline
\end{tabular}

improve the quality of the grid-connected current waveform. The expression of the notch filter is

$$
G^{\prime}(s)=\frac{s^{2}+\left(\omega_{\mathrm{o}}\right)^{2}}{s^{2}+K \omega s+\left(\omega_{\mathrm{o}}\right)^{2}},
$$

where $K$ is the controller coefficient and $\omega_{0}$ is taken as $3 \omega$.

\section{Simulation Result Analysis}

Establish a three-phase LCL grid-connected inverter simulation model based on MATLAB/Simulink, analyze the steady-state and dynamic performance of the system, and verify the correctness of the proposed method.

6.1. Three-Phase Power Grid Balance Conditions. The voltage parameters of the three-phase grid-side grid are $u_{\text {ga }}=380 \angle 0^{\circ}$, $u_{\mathrm{gb}}=380 \angle-120^{\circ}$, and $u_{\mathrm{gc}}=380 \angle 120^{\circ}$, and the voltage waveform is shown in Figure 7.

The simulation parameters are shown in Table 2.

Figure 8 shows the simulation results when using the self-interference immunity proposed in this article and the improved DDSRF-PLL control. It can be seen that the gridside voltage of the system and the grid-connected current maintain the same phase, and the grid-connected current THD is $1.69 \%$, which conforms to IEEE std. 929-2000 standard.

6.2. Three-Phase Power Grid Unbalance Conditions. The three-phase grid voltage parameters are $u_{\text {ga }}=380 \angle 0^{\circ}$, $u_{\mathrm{gb}}=280 \angle-137^{\circ}$, and $u_{\mathrm{gc}}=280 \angle 137^{\circ}$, and the other simulation parameters are consistent with the parameters in Table 2, and the voltage waveform is shown in Figure 9.

When the traditional PI control is used, the simulation results of the three-phase LCL grid-connected inverter during steady-state operation are shown in Figure 10, and the grid-connected reference current is $200 \mathrm{~A}$. It can be seen that although the grid-side voltage and the grid-connected current maintain the same phase, the three-phase gridconnected current output is unbalanced, and the amplitudes are obviously different. The grid-connected current has a large third harmonic content, accounting for about $5.70 \%$, and the THD is $5.96 \%$, which does not conform to the IEEE Std.929-2000 standard.

Figure 11 is the simulation result when the system adopts the active disturbance rejection and improved DDSRF-PLL control suggested in this paper. From the figure, it can be 


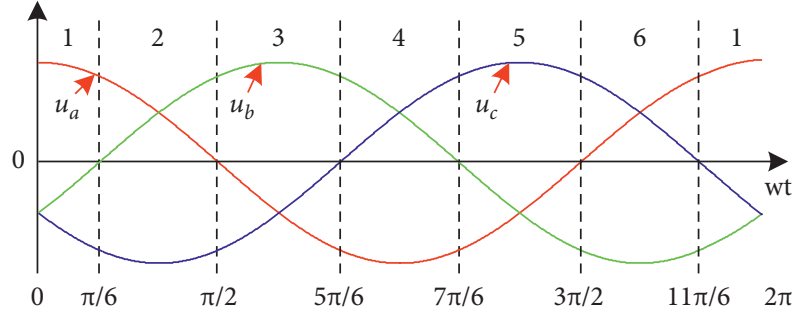

(a)

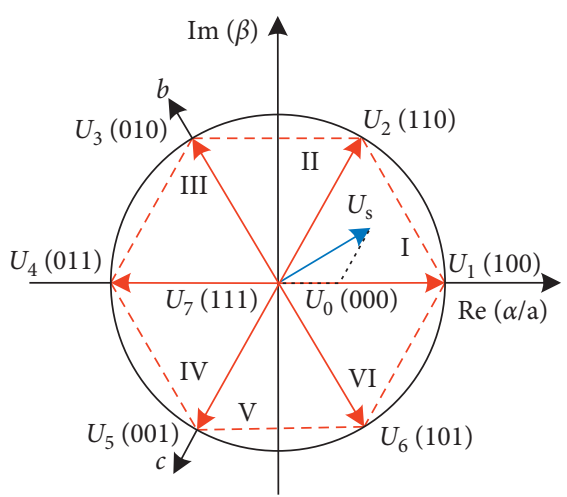

(b)

FIGURE 6: 6 sector modulation schematic diagram: (a) 6 sector grid voltage and sector distribution, and (b) voltage vector and sector spatial distribution.

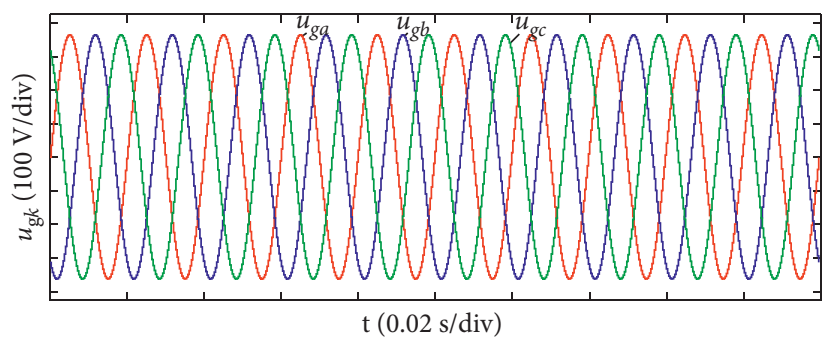

FIgURE 7: Three-phase balanced grid voltage.

TABLE 2: Switch status and sector division.

\begin{tabular}{lcc}
\hline Quantity & Symbol & Value \\
\hline Grid frequency & $f$ & $50 \mathrm{~Hz}$ \\
Grid side inductance & $\mathrm{L}_{\mathrm{g} k}$ & $1 \mathrm{mH}$ \\
AC side inductance & $\mathrm{L}_{k}$ & $1 \mathrm{mH}$ \\
AC side capacitance & $\mathrm{C}_{k}$ & $100 \mathrm{uF}$ \\
DC side capacitance & $\mathrm{C}$ & $500 \mathrm{uF}$ \\
Switching frequency & $f_{\mathrm{s}}$ & $10 \mathrm{kHz}$ \\
Sampling frequency & $f_{\mathrm{sa}}$ & $10 \mathrm{kHz}$ \\
DC side voltage & $u_{\mathrm{dc}}$ & $800 \mathrm{~V}$ \\
\hline
\end{tabular}

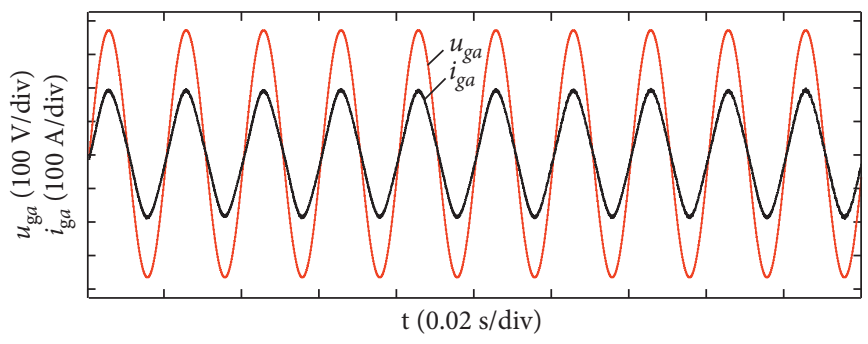

(a)

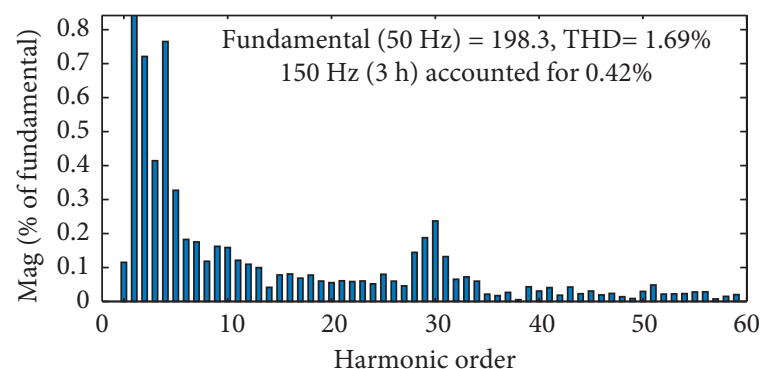

(b)

FIGURE 8: Simulation results of the proposed method when the power grid is balanced. (a) Grid side a-phase current and voltage, and (b) grid-side current spectrum analysis.

seen that the grid-side voltage and the grid-connected current maintain the same phase, and the three-phase gridconnected current output is balanced. Compared with the traditional PI control, the third harmonic content of the grid-connected current of this method is significantly reduced, accounting for about $0.31 \%$, and the grid-connected 


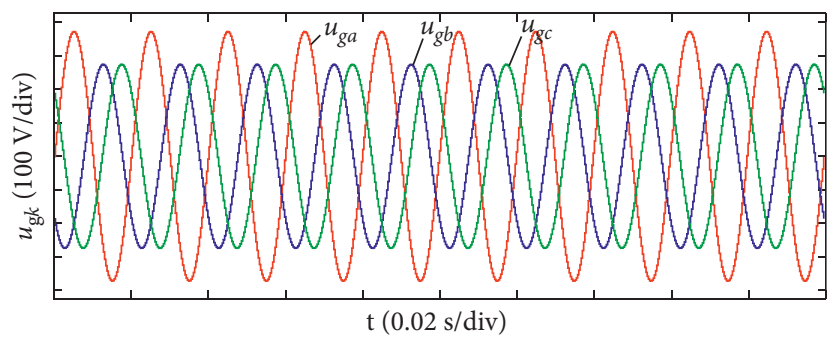

FIGURE 9: Three-phase unbalanced grid voltage.

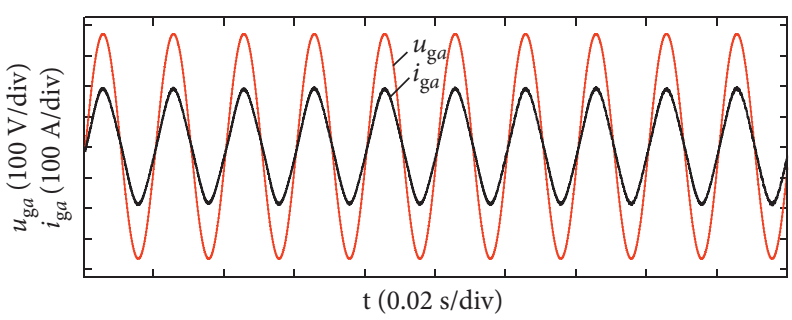

(a)

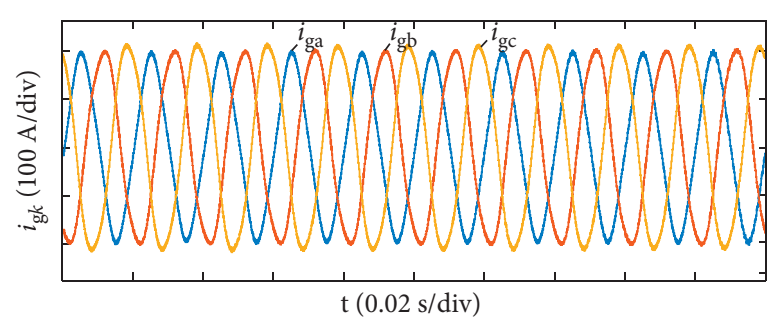

(b)

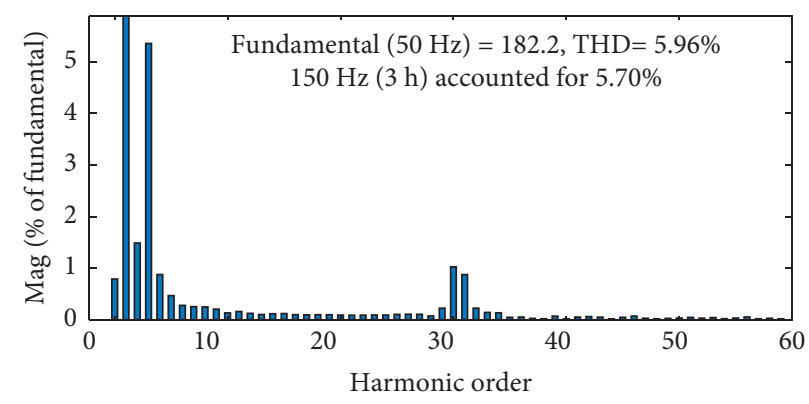

(c)

Figure 10: The simulation results of traditional PI: (a) grid side a-phase current and voltage, (b) grid-side current, and (c) grid-side current spectrum analysis.

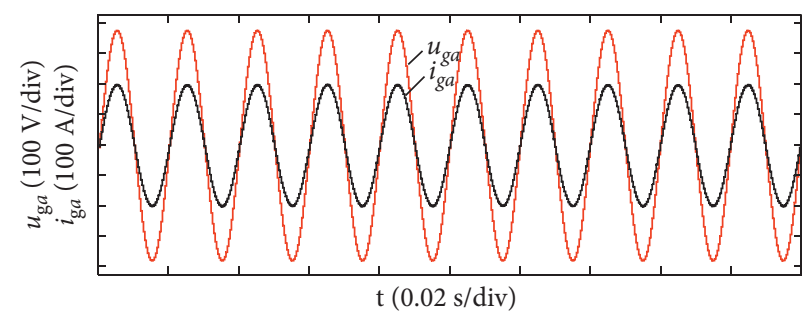

(a)

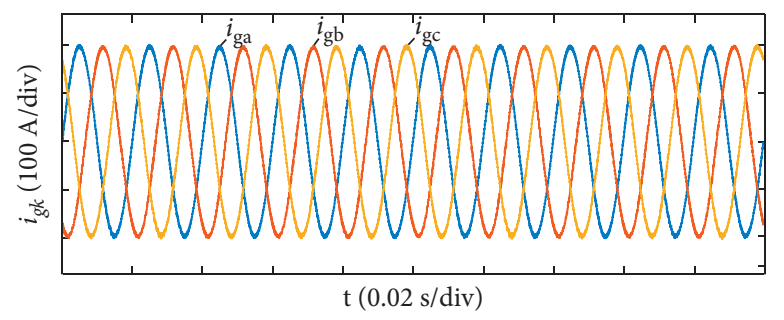

(b)

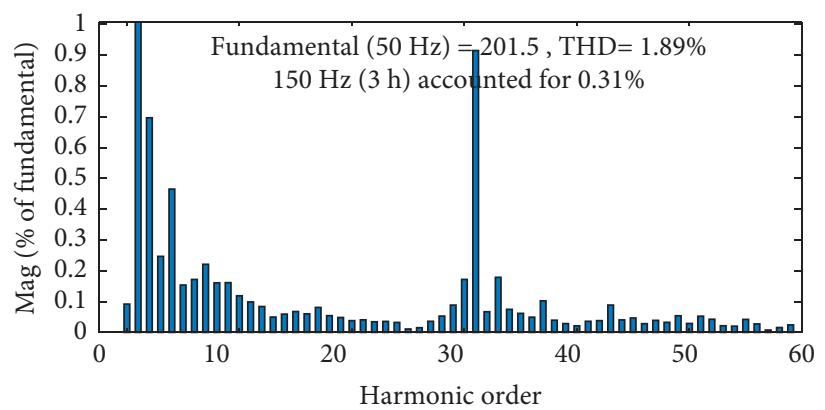

(c)

FIGURE 11: Simulation results of active disturbance rejection control: (a) grid side a-phase current and voltage, (b) grid-side current, and (c) grid-side current spectrum analysis. 

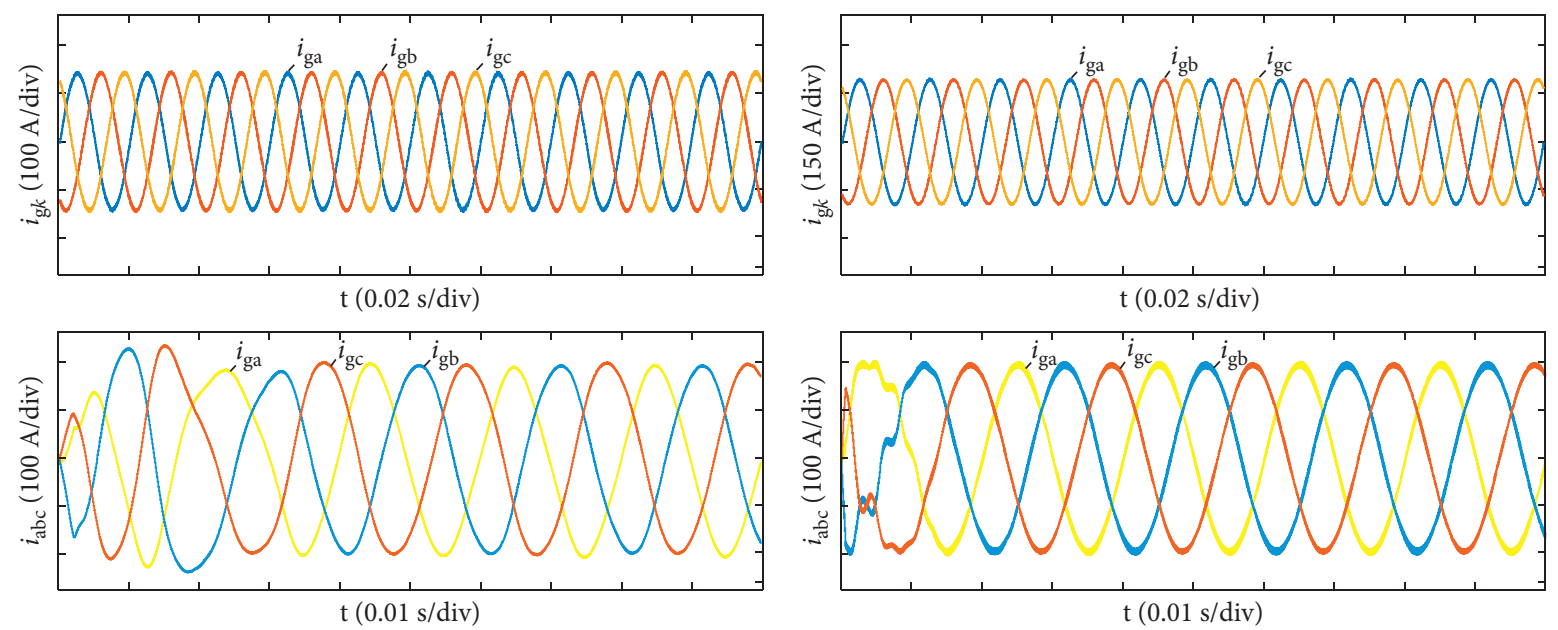

(a)

(b)

FIGURE 12: Simulation results of active disturbance rejection control method at different powers: (a) grid-side current waveform when the reference current is $150 \mathrm{~A}$ and (b) grid-side current waveform when the reference current is $250 \mathrm{~A}$.

current THD is $1.89 \%$, which conforms to the IEEE std. 929-2000 standard.

Figure 12 shows the output waveforms of the threephase grid-connected current when the reference current is $150 \mathrm{~A}$ and $250 \mathrm{~A}$, respectively. It can be seen that, under different operating conditions, the three-phase grid-connected current output is balanced. The simulation results show that the three-phase LCL grid-connected inverter has good steady-state performance under different output powers under unbalanced conditions.

\section{Conclusion}

This paper proposes a method to reduce the influence of harmonics on the phase-locked loop structure through a low-pass filter and designs a current active disturbance rejection controller, which solves the problem of the threephase LCL type transformer inverter operating in unbalanced grid problems in voltage conditions. Based on the simulation results under balanced and unbalanced grid voltages, the following conclusions can be drawn:

(1) The optimized phase-locked structure has excellent performance; the method proposed in this paper can keep the grid-side voltage and current in the same phase under the balanced grid voltage, and the gridconnected current THD is only $1.69 \%$, and the system has good steady-state performance.

(2) When the traditional PI loop is used under unbalanced grid voltage, the grid-connected current threephase output is unbalanced, the amplitude is obviously different, the third harmonic content is large, and the THD value is greater than $5 \%$.

(3) The method proposed in this paper enables the gridconnected inverter to have superior performance under unbalanced conditions. When operating at three different output powers, the grid-connected current is output in three phases, and the third harmonic content is significantly reduced, the THD value is $1.89 \%$, and it conforms to the IEEE std. 929-2000 standard.

\section{Data Availability}

The data used to support the findings of this study are available from the corresponding author upon request.

\section{Disclosure}

A preprint has previously been published [31].

\section{Conflicts of Interest}

The authors declare that they have no conflicts of interest.

\section{Acknowledgments}

This work was supported in part by the National Natural Science Foundation of China, under grant number 61863023.

\section{References}

[1] H. Jafarian, S. Bhowmik, and B. Parkhideh, "Hybrid current-/ voltage-mode control scheme for distributed AC-stacked PV inverter with low-bandwidth communication requirements," IEEE Transactions on Industrial Electronics, vol. 65, no. 1, pp. 321-330, 2018.

[2] H. Fathabadi, "Improving the power efficiency of a PV power generation system using a proposed electrochemical heat engine embedded in the system," IEEE Transactions on Power Electronics, vol. 34, no. 9, pp. 8626-8633, 2018.

[3] A. Menti, D. Barkas, S. Kaminaris, and C. S. Psomopoulos, "Supraharmonic emission from a three-phase PV system connected to the LV grid," Energy Reports, vol. 7, no. 5, pp. 527-542, 2021.

[4] X. Li, X. Xing, C. Zhang, A. Chen, C. Qin, and G. Zhang, "Simultaneous common-mode resonance circulating current and leakage current suppression for transformerless three- 
level T-type PV inverter system," IEEE Transactions on Industrial Electronics, vol. 66, no. 6, pp. 4457-4467, 2019.

[5] O. S. Bayhan and H. Komurcugi, "Model-based current control strategy with virtual time constant for improved dynamic response of three-phase grid-connected VSI," IEEE Transactions on Industrial Electronics, vol. 66, no. 6, pp. 4156-4165, 2019.

[6] H. Komurcugil, N. Altin, S. Ozdemir, and I. Sefa, "Lyapunovfunction and proportional-resonant-based control strategy for single-phase grid-connected VSI with LCL fulter," IEEE Transactions on Industrial Electronics, vol. 63, pp. 2838-2849, 2016.

[7] N. Panten, N. Hoffmann, and F. W. Fuchs, "Finite control set model predictive current control for grid-connected voltagesource converters with LCL filters: a study based on different state feedbacks," IEEE Transactions on Power Electronics, vol. 31, no. 7, pp. 5189-5200, 2016.

[8] H. Hu, F. Feng, and T. Wang, "Open-circuit fault diagnosis of NPC inverter IGBT based on independent component analysis and neural network," Energy Reports, vol. 6, no. 9, pp. 134-143, 2020.

[9] J. C. Giacomini, L. Michels, M. C. Cavalcanti, and C. Rech, "Modified discontinuous PWM strategy for three-phase gridconnected PV inverters with hybrid active-passive damping scheme," IEEE Transactions on Power Electronics, vol. 35, no. 8, pp. 8063-8073, 2020.

[10] Z. Fu, Z. Zhang, and Y. Dong, "Research on LCL three-phase photovoltaic grid-connected inverter under weak grid conditions," Acta Solar Energy, vol. 42, no. 04, pp. 193-199, 2021.

[11] A. Benali, M. Khiat, T. Allaoui, and M. Denaï, "Power quality improvement and low voltage ride through capability in hybrid wind-PV farms grid-connected using dynamic voltage restorer," IEEE Access, vol. 6, pp. 68634-68648, 2018.

[12] W. Yao, Y. Yang, X. Zhang, F. Blaabjerg, and P. C. Loh, "Design and analysis of robust active damping for LCL filters using digital notch filters," IEEE Transactions on Power Electronics, vol. 32, no. 3, pp. 2360-2375, 2017.

[13] W. Bian, F. Li, and J. Zhao, "Active damping method of digital notch filter based on LCL inverter," Power System Protection and Control, vol. 42, no. 21, pp. 14-19, 2017.

[14] N. Lai and K. Kim, "Robust control scheme for three-phase grid-connected inverters with LCL-filter under unbalanced and distorted grid conditions," IEEE Transactions on Energy Conversion, vol. 33, no. 2, pp. 506-515, 2018.

[15] X. Guo, X. Zhang, and Z. Lu, "Power/current quality coordinated control strategy of photovoltaic grid-connected inverters under unbalanced grid voltages," Proceedings of the Chinese Society for Electrical Engineering, vol. 34, no. 3, pp. 346-353, 2014.

[16] Imdadullah, S. M. Amrr, M. S. J. Asghar, and A. Iqbal, "Comprehensive performance analysis of flexible asynchronous AC link under various unbalanced grid voltage conditions," Energy Reports, vol. 7, pp. 750-761, 2021.

[17] H. S. Kwanghee Nam and K. Nam, "Dual current control scheme for PWM converter under unbalanced input voltage conditions," IEEE Transactions on Industrial Electronics, vol. 46, no. 5, pp. 953-959, 1999.

[18] M. Reyes, P. Rodriguez, S. Vazquez, A. Luna, R. Teodorescu, and J. M. Carrasco, "Enhanced decoupled double synchronous reference frame current controller for unbalanced gridvoltage conditions," IEEE Transactions on Power Electronics, vol. 27, no. 9, pp. 3934-3943, 2012.

[19] T. L. Nguyen and H. H. Lee, "Simplified model predictive control for AC/DC matrix converters with active damping function under unbalanced grid voltage," IEEE Journal of Emerging and Selected Topics in Power Electronics, vol. 8, no. 3, pp. 2907-2917, 2020.

[20] X. Guo, S. Sun, X. Liang, Y. Ning, and D. Zheng, "Model predictive current control for two-phase switches clamping of three-phase inverter," Energy Reports, vol. 6, no. 9, pp. 164-172, 2021.

[21] Y. Lin, S. Tao, and X. Xiao, "DC voltage control of gridconnected inverters under imbalanced voltage," Power System Technology, vol. 39, no. 6, pp. 1643-1649, 2015.

[22] W. Zhang, H. Wang, and Y. Ren, "Investigation on control of three-phase grid-connected inverters under unbalanced grid voltage conditions," Transactions of China Electrotechnical Society, vol. 25, no. 12, pp. 103-111, 2010.

[23] R. A. Fantino, C. A. Busada, and J. A. Solsona, "Optimum PR control applied to LCL filters with low resonance frequency," IEEE Transactions on Power Electronics, vol. 33, no. 1, pp. 793-801, 2018.

[24] Y. Li and X. Gao, "Power feedforward T-type three-phase three-level photovoltaic grid-connected inverter fast finite set model predictive control," Acta Solar Energy, vol. 40, no. 11, pp. 3062-3070, 2019.

[25] R. Guzman, L. G. de Vicuña, A. Camacho, J. Miret, and J. M. Rey, "Receding-horizon model-predictive control for a three-phase VSI with an LCL filter," IEEE Transactions on Industrial Electronics, vol. 66, no. 9, pp. 6671-6680, 2019.

[26] J. Lu, M. Savaghebi, A. M. Y. M. Ghias, X. Hou, and J. M. Guerrero, "A reduced-order generalized proportional integral observer-based resonant super-twisting sliding mode control for grid-connected power converters," IEEE Transactions on Industrial Electronics, vol. 68, no. 7, pp. 5897-5908, 2019.

[27] Z. Dai, Z. Zhang, Y. Yang, F. Blaabjerg, Y. Huangfu, and J. Zhang, "A fixed-length transfer delay based adaptive frequency-locked loop for single-phase systems," IEEE Transactions on Power Electronics, vol. 34, no. 5, pp. 4000-4004, 2019.

[28] J. Chen, Y. Hwang, C. Chang, Y. Ku, and C. Yu, "A sub-1 $\mu$ s fast-response buck converter with adaptive and frequencylocked controlled techniques," IEEE Transactions on Industrial Electronics, vol. 66, no. 3, pp. 2198-2203, 2019.

[29] L. Yu, D. Wang, Z. Liu, D. Zheng, and W. Li, “A DPS-PLL based rotor position estimation method for permanent magnet wind turbine," Energy Reports, vol. 7, no. 6, pp. 502-507, 2021.

[30] H. Pan, Z. Li, and T. Wei, "A novel phase-locked loop with improved-dual adaptive notch filter and multi-variable filter," IEEE Access, vol. 7, pp. 176578-176586, 2019.

[31] J. Yang and N. Meng, Active disturbance rejection control of three-phase lcl grid-connected inverter under unbalanced grid voltage, SSRN, Rochester, NY. USA, . 